\title{
Crisis response to COVID-19: Elements for a successful virtual event transition
}

\author{
Emily E. Hopkins;, Jennifer J. Wasco, Kathleen C. Spadaro, MaryDee Fisher, Lora Walter, Marilu Piotrowski \\ School of Health Sciences, Chatham University, Pittsburgh, PA, United States
}

Received: October 9, 2020

Accepted: November 15, $2020 \quad$ Online Published: November 18, 2020

DOI: $10.5430 /$ jnep.v11n3p36

URL: https://doi.org/10.5430/jnep.v11n3p36

\begin{abstract}
Rapid onset of the COVID-19 pandemic necessitated a crisis response among academic institutions to provide continuity of learning, in an alternate structure, as on-ground campuses across the country closed. This led to a myriad of virtual and online learning formats for collegiate programs. Ironically, it also altered plans among existing online programs scheduled for in-person, on-campus residency requirements. Complying with newly imposed institution regulations, a small private university in southwestern Pennsylvania was required to move their traditional on-ground Doctor of Nursing Practice residency to a virtual platform. Leveraging online tools and creating a new format was needed to effectively meet program requirements. Success of the residency was dependent upon a straightforward information technology program with adequate support and detailed student resources. Residency structure from the existing on-ground program was combined with online tools to successfully adapt the event into a virtual format. Feedback provided by students and faculty was reviewed to streamline and improve future transitions. The advent of COVID-19 created an opportunity for the nursing program to learn how to transition a key educational on-ground event to a successful virtual one. Although crisis response is common in the clinical setting, adapting to meet critical needs is also essential to the academic environment. Rapid response with forming a virtual residency has provided a foundation for continued growth and refinement of on-ground events being moved to an online platform during a time of crisis. Critical elements for transitioning to the virtual environment are summarized.
\end{abstract}

Key Words: COVID-19, Pandemic, Crisis, Doctor of nursing practice, Residency, Virtual

\section{INTRODUCTION}

The pandemic of 2020 created challenges across the globe to lessen its threat and severity among all aspects of life. The discovery of the novel coronavirus, named severe acute respiratory syndrome coronavirus 2 , also referred to as COVID-19, set into motion a series of events leading to the World Health Organization (WHO) classifying it as a pandemic. ${ }^{[1]}$ As a result, federal, state, and local government orders were issued to slow the spread of the disease, with directives including the closure of businesses and shelter in place of individu- als to their households. These orders immediately affected higher learning institutions as campuses closed, sending students home to complete learning virtually. Both faculty and students were impacted due to travel restrictions and quarantine requirements on a state level that had families at home with children, limited supplies and support, and more time demands to manage the crisis.

Nursing, as a discipline, is often focused on crises within the clinical environment but was now challenged with a farreaching crisis in the academic arena. While on-ground

*Correspondence: Emily E. Hopkins; Email: ehopkins@ chatham.edu; Address: School of Health Sciences, Chatham University, Pittsburgh, PA, United States. 
nursing programs were struggling to create virtual learning opportunities, online advanced nursing degree programs found government restrictions impacted existing virtual curriculums that contained in-person learning requirements such as residency. A southwestern Pennsylvania university had a long-established online Doctor of Nursing Practice (DNP) program that faced immediate challenges arising from the restrictions. The DNP program requires an on-ground residency where students are required to travel to the brick and mortar campus and share their capstone project as part of degree fulfillment. This event was scheduled to occur in April 2020, with over 35 students slated to present their evidencebased practice projects. When the American Association of Colleges of Nursing joined state governors to issue guidelines recommending the limit of student travel, the on-ground residency could no longer occur. ${ }^{[2]}$ As a result, the university faculty were presented with the challenge of rapidly moving to a virtual residency program since this requirement could not be omitted from the curriculum. Although academic institutions were familiar with crisis planning for individual student situations and larger scale disasters, ${ }^{[3]}$ intervening for pandemic circumstances was unchartered territory. Therefore, this article will share the experience of swiftly moving an in-person student event online. Important elements of the transition from an on-ground residency to a successful virtual residency in a time of crisis will be summarized to assist with replication by other nursing programs.

\section{BACKGROUND}

A crisis is experienced during times of difficulty and often requires an important decision to be made among those involved. Circumstances surrounding the crisis are often negative and unexpected creating a stressful environment. ${ }^{[4]}$ Moreover, how the emergent event is handled is critical for those whom it will impact. Some forms of crises are well known, enabling institutions to prepare for them. The nursing profession and academia are two institutions who have several known critical situations for which they have education and protocols set as standards to follow should a crisis occur.

Crises have always played an integral role in the nursing profession. In fact, a crisis is often central to nursing care. This crisis can be based on numerous types of clinical scenarios such as acute physical trauma, a suddenly decompensating patient, family dynamics, or a major environmental event such as a hurricane or wildfire. Further, given the nature of this work, nurses themselves may be functioning in a crisis mode due to a high stress environment resulting in anxiety and causing burn-out. Therefore, nursing education is filled with case scenarios and preparation to better function within the crisis setting. Often, nursing education utilizes a safe and effective environment such as simulation for teaching crisis recognition and intervention skills. ${ }^{[5,6]}$

Academic institutions too have learned to thrive in a crisis setting. Given the competitive nature of higher education, institutions are prepared for different forms of threat to daily institutional functions based on a business crisis management plan. ${ }^{[7]}$ Higher education also has crisis management or safety plans in place to prevent or minimize harm to faculty, staff, and the student body as well as aid in the recovery process for traumatic events and natural disasters. ${ }^{[8]}$ Additional policies and resources exist to assist students with personal academic crises as well.

However, the COVID-19 pandemic created a new kind of crisis for nursing education and academia. Protocols written based on previously experienced events could no longer be used. Instead, limited information and data combined with government issued stay-at-home orders drove extensive changes among institutions. This left faculty in search of ways to reimagine traditional classroom learning strategies and required the conversion of on-ground events to virtual proceedings. Further, it necessitated change among online nursing programs that required an in-person residency. Currently, there is no published research literature on best practices to aid with this on-ground and in-person transition to a virtual or online environment.

\section{ON-GROUND DNP RESIDENCY}

Since its inception 12 years ago, an on-ground residency has been part of the small private university's DNP program. The DNP on-ground residency is a key component to online doctoral education, allowing students to demonstrate their evidence-based practice expertise and competency in an area of nursing practice through a scholarly poster presentation. Given the fully online nature of the program, the on-ground residency became the only opportunity for students to visit the campus and personally interact with staff and faculty. Therefore, the spirit of having an on-ground residency was intended to be an interconnected experience, and a time to promote collaboration, collegiality, and community amongst students and faculty who were otherwise limited to virtual communications.

The two-day long residency follows an agenda combining an education experience with professional and interpersonal connections that begins with a welcome reception and closes with student evaluations. The main focus of residency is student poster presentations of their evidence-based practice capstone project. Faculty, fellow students, and staff visit each poster and engage with the student presenter. Poster 
sessions are held over two days, with half of the student cohort presenting each day. The DNP faculty assesses student projects utilizing a formative oral rubric to ensure program consistency and student competency achievement. Based on the information gathered during the poster review, course and programmatic changes are made to ensure program learning outcomes are achieved. After poster presentations, DNP faculty members hold small roundtable discussions with their assigned advisees. This provides the opportunity to address future project implementation and program questions in an open and relaxed environment. Throughout the residency program, there are also opportunities for campus tours, visits to the bookstore, regalia purchasing, and meeting the director of alumni affairs. A group photo is a culminating event at the end of residency. The group photo is shared as a memory of the lived experience amidst colleagues, faculty, and the campus community.

\section{Crisis RESPONSE TRANSITION PLAN- NING FOR VIRTUAL RESIDENCY}

Nursing program leadership monitored the pandemic crisis as it progressed. Once closures were announced, faculty recognized that an in-person residency would not be possible. The decision was made to host residency virtually, and students were notified of the change by program administration. Since residency is a requirement for degree conferral, the virtual event would still require the core activities of poster presentation reviews and small group discussions. To ensure a successful virtual residency, transition planning among faculty and staff was vital. Remote video meetings and email correspondence enabled a rapid response to the crisis. Several important components became the central focus for relocating the on-ground, in-person residency to a virtual platform. These components were the selection of a virtual platform that was easy to navigate and had information technology (IT) support, developing student resources, building a virtual hub to house student resources, designing a format for the event, and revising the student residency evaluation form.

The first step in transition planning was consulting with the IT and instructional technology teams to identify options for hosting the residency. It was determined that leveraging the Zoom video conferencing service would be utilized due to its simplified usability and the ability to connect across any device. However, higher IT demands due to the pandemic resulted in minimal technology support for the actual live virtual residency event. The nursing program assistants and practice experience faculty were voluntarily trained to be the sole source of virtual residency IT support to address the limited IT support resources. To fulfill this role, each willingly served as a session moderator. The session moderator primarily guided residency operations offering general scripted knowledge such as session introductory information, keeping track of presentation time slots, offering appropriate alerts as needed for event timing, and providing immediate IT support for students virtually.

Once the virtual platform and additional training needs had been determined, the development of the event content and proceedings began. While planning for the virtual residency structure, additional pandemic consequences became evident. Clinical staffing mandates and childcare needs were creating time constraints for the majority of DNP students. Therefore, the format was condensed into seven small groups of four to five students per virtual residency session compared to the larger group setting during the on-ground event. The overall length of residency was shortened to three hours. Each student could schedule their time slot via an Excel spreadsheet housed on the university's virtual hub, and then faculty were assigned to facilitate poster presentations and discussions in one of the seven time slots.

Additional student resources were designed to outline virtual residency poster presentation expectations clearly. This included both a document and recorded Panopto on-demand video to provide both visual and audio instruction on poster presentation and design guidelines. Since the DNP program was entirely online except for the residency, the current learning management system was leveraged to include a DNP residency virtual hub housing all necessary resources for students. In addition to these resources, technical instructions for accessing Zoom and a submission link to upload student residency posters were provided. Most importantly, a question and answer forum was available for the students to ask questions about the virtual residency format.

Although holding a virtual residency would lose many personal qualities of on-ground residency, efforts were made to provide consistency with traditional formatting. Each small group began with faculty and student introductions. Then, a lead faculty member interacted with poster presenters and used the same formative assessment as on-ground residency. Additional faculty and other university administration members, including the dean and university president, joined sessions to engage in the live student poster presentations as their schedules permitted. To have an itinerary closely resembling on-ground residency, time was allotted for faculty and student questions following each poster presentation. After each student presented and posed questions were answered, all active participants had a break prior to regrouping for a round table discussion about upcoming capstone implementation and DNP program completion. 
To properly capture and reflect upon students' experience with virtual residency, the nursing program administrative assistant emailed a student evaluation survey link immediately following the virtual residency with a formal completion request from the program director. As this was the university's first virtual residency, the existing on-ground DNP residency evaluation required revision to capture the students' experience better and address the crisis response with virtual adaptation. Using DNP faculty feedback on survey content, modifications were made, and the survey was uploaded into the university's Qualtrics software. The anonymous survey consisted of 14 items, the first nine based on a 5-point Likert scale, and the remaining six open-ended questions. Survey responses were later assessed to determine the quality of the virtual academic experience and serve as a baseline for future program revisions based on critical feedback.

\section{VIRTUAL RESIDENCY FUTURE DIREC- TIONS}

The goal of DNP residency remained unchanged, as it offered students the opportunity to showcase their significant capstone work to date. However, the virtual delivery format offered some barriers to overcome. Preparing for this event as a faculty member included the desire to continue in the spirit of the on-ground residency, to promote students' creativity, and properly encourage project implementation ideas. However, this needed to occur within a very narrow (15-minute) presentation timeframe due to student work and family demands resulting from the pandemic. Thus, shortly before the virtual poster presentations, faculty were able to view assigned students' posters. This preview allowed faculty to become familiar with the students' clinical problems of interest and note potential content gaps that would need addressed in focused conversations during the virtual presentation dialogue. Although students were well prepared, hosting faculty noted unanticipated difficulties with the presenting student's nonverbal cues, given limitations of the computer screen capturing only facial expressions. In addition, faculty were concerned that questions directed toward individual students might be misinterpreted and viewed as student prodding, thus causing unintended angst and/or embarrassment. Subsequently, many faculty members sent individualized and encouraging follow-up student emails to reinforce a job well done and offer another connectivity touchpoint.

As with any crisis response, reflection on the virtual residency experience occurred and many areas for improvement were identified. With much foresight, faculty shared ideas to lay the foundation of "a new normal", while preserving the intent, climate, and approach of traditional on-ground residency program. As such, future directions for upcoming virtual residencies may include uploading student posters with more lead time for faculty viewing and preparation. The addition of a more interactive synchronous and less structured opportunity for scholarly exchange of ideas between faculty and students was suggested to encourage conversation between peers to preserve a spirit of networking and collegiality. Also recommended was more faculty in attendance at each session as well as break-out sessions for one-to-one discussion as needed.

Table 1. Elements for successful transition to virtual events

\begin{tabular}{lll}
\hline Elements & & \\
\hline \multirow{2}{*}{ Anticipatory Planning } & - & Monitor current information related to Covid-19 \\
& - & Track how current circumstances related to Covid-19 can impact student program progression. \\
\hline \multirow{2}{*}{ Communication Strategies } & - & Leverage electronic resources (email, Zoom, and LMS) for rapid communication \\
& - & Keep faculty, student, and staff informed of virtual residency content/resources \\
\hline \multirow{3}{*}{ Project Management } & - & Establish frequent planning meetings with faculty and staff via video conferencing \\
& - & Identify an IT platform that best fits the needs of the virtual event \\
& - & Create support materials; visual and auditory, to support learner needs \\
\multirow{2}{*}{ Program Evaluation } & - & Create a formal student evaluation of the virtual experience \\
& - & Review evaluation results and debrief with faculty \\
& - & Determine items needed to be change for future events \\
& - & Plan how to incorporate recommended changes \\
\hline
\end{tabular}

\section{DisCuSSION}

Although the COVID-19 pandemic created many challenges, including academic crises, a small private university in southwestern Pennsylvania was able to rapidly plan and execute the transition of an on-ground DNP residency to a virtual format. The success of this event was dependent upon many

Published by Sciedu Press crucial elements summarized in Table 1. Other academic institutions may find these elements applicable and useful when encountering a crisis that necessitates rapid transition from an on-ground gathering to a virtual event. Through shared efforts and crisis intervention, faculty and staff altered the established format of an educational requirement 
yet still accomplished the same main objectives for a substantial educational experience in a time of uncertainty. A once formal in-person event becoming a virtual experience for faculty, students, and the staff was an unprecedented experience. Based on this experience, an awareness was created that additional research is needed for best practices when converting on-ground events to a virtual environment.

\section{Conclusion}

The COVID-19 pandemic significantly impacted academia and forced institutions into an unchartered crisis manage- ment plan. Faculty and staff were thrust into employing new strategies and learning new technologies to meet student needs in a virtual environment. Nevertheless, by anticipating needs, communicating effectively, creating a management plan for virtual transition, and evaluating the virtual event, academic rigor can be upheld, and program outcomes can be achieved.

\section{CONFlicts OF INTEREST Disclosure}

The authors declare that there is no conflict of interest.

\section{REFERENCES}

[1] AACN: Considerations for Covid-19 Preparedness and Response to U.S. Schools of Nursing. [Internet] Washington, DC: American Association of Colleges of Nursing; c2020 [cited 2020 Sept 12]. Available from: https : //www . aacnnursing.org/News-Information/F act-Sheets/Nursing-Shortage

[2] WHO: WHO Director-General's Opening Remarks at the Media Briefing on Covid-19 - 11 March, 2020. [Internet] WHO; c2020 [cited 2020 Sept 12]. Available from: https://www . who.int/dg/speeches/detail/who-directo $r$-general-s-opening-remarks-at-the-media-briefin g-on-covid-19---11-march-2020

[3] Schonfeld, DJ, Newgass, S. School crisis response initiative. [Internet] Washington, DC: US Department of Justice, Office of Justice Programs, Office for Victims of Crime; c2003 [cited 2020 Sept 12]. Available from: https://ovc.ojp.gov/sites/g/files/xyckuh226/files/ publications/bulletins/schoolcrisis/welcome.html

[4] Merriam-Webster: Crisis. [Internet] Merriam-Webster, Incorporated; c2020 [cited 2020 Nov 10]. Available from: https://www.merria $\mathrm{m}$-webster.com/dictionary/crisis

[5] Sofer, D. The value of simulation in nursing education. American Journal of Nursing. 2018 April; 118(4): 17-18. https ://doi .org/ 10.1097/01. NAJ .0000532063.79102.19

[6] Kim J., Park JH, Shin S. Effectiveness of simulation-based nursing education depending on fidelity: a meta-analysis. BMC Medical Education. 2016; 16: 152-160. PMid:27215280 https ://doi .org/10 .1186/s12909-016-0672-7

[7] Lapovsky L. The changing business model for colleges and universities. [Internet] Forbes; c2018 [cited 2020Nov10]. Available from: https://www. forbes. com/sites/lucielapovsky/201 8/02/06/the-changing-business-model-for-colleges-a nd-universities $/$ ?sh=81620cf5ed59

[8] Chatham University. Safety policies \& programs. [Internet] Pittsburgh, PA: Chatham University; c2020 [cited 2020 Nov 10] Available from: https://www.chatham.edu/student-exper ience/transportation-and-safety/safety-policies-a nd-programs.html 